\title{
Vertebral distribution of Pott's disease of the spine among adult Sudanese patients in Khartoum, Sudan
}

\author{
Elwathiq Khalid Ibrahim ${ }^{1}$, Elbashir Gusm Elbari Ahmed ${ }^{1}$, Nour Eldaim Elnoman Elbadawi ${ }^{1,2, *,}$ \\ Mamoun Majzoub Mohammed ${ }^{1}$
}

${ }^{1}$ Faculty of Medicine, Kassala University, Kassala, Sudan

${ }^{2}$ Department of Biochemistry, Faculty of Medicine \& Health Sciences, University of Kassala, Kassala, Sudan

\section{Email address:}

noureldaim@hotmail.com (N. E. E. Elbadawi)

\section{To cite this article:}

Elwathiq Khalid Ibrahim, Elbashir Gusm Elbari Ahmed, Nour Eldaim Elnoman Elbadawi, Mamoun Majzoub Mohammed. Vertebral Distribution of Pott's Disease of the Spine among Adult Sudanese Patients in Khartoum, Sudan. American Journal of Health Research. Vol. 2, No. 3, 2014, pp. 93-96. doi: 10.11648/j.ajhr.20140203.13

\begin{abstract}
This was a cross-sectional hospital-based study conducted at Neurology Department, Shaab Teaching Hospital, Khartoum in a period of two years. The aim of the study was to determine the most affected region of the spine in adult Sudanese patients with Pott's disease. Hundred patients with clinical suspicion of spinal TB were enrolled in the study. Clinical history and examination, investigations for TB and imaging studies were performed. Midthoracic spines (T5 - T8) and lower thoracic spines (T9 - T12) were found to be the most regions affected with tuberculosis. In 20 cases (20\%) the disease affected the upper thoracic vertebrae $(\mathrm{T} 1-\mathrm{T} 4)$ and in 12 cases $(12 \%)$ it was in the lumbar spines. Only four patients (4\%) were having cervical spinal tuberculosis. The higher affection of the mid thoracic and lower thoracic levels of the spine was thought to be attributed to infection from combination of haematogeneous, lymphatic and direct invasion.
\end{abstract}

Keywords: Pott's Disease, Spinal Tb, Skeletal Tuberculosis, Kyphosis

\section{Background}

Tuberculosis (TB) is a worldwide major health problem particularly in developing countries. It is a leading cause of death among poorest societies. TB competes with HIV infection as top tow killers from infectious diseases ${ }^{1}$. According to the site of involvement, TB is classified into two major categories; pulmonary and extrapulmonary TB. As one of oldest varieties of extrapulmonary TB, spinal TB is an ancient disease. It has been found in old Egyptian mummies since $3400 \mathrm{BC}^{2}$. The name Pott's disease was came after Sir Percival Pott, an English surgeon who was the first to demonstrate tuberculosis infection of the spine in his monograph in $1779^{3}$.

Spinal TB, the second most common presentation of extrapulmonary tuberculosis (EPTB), comprises in most series about $50 \%$ of cases of skeletal $\mathrm{TB}^{4}$. Pott's disease, is characterized by destruction of vertebral bodies of the adjacent vertebrae and vertebral disc space collapse, resulting in severe and progressive kyphotic deformity known as gibbus. This angulation of the spine coupled with formation of granulation tissue with fragments of destructed elements of bone can lead to cord compression and subsequent neurological symptoms. Spinal tuberculosis is considered as one of the most dramatic pathologies resulting from infection with Mycobacterium tuberculosis ${ }^{5}$. The disease usually reach the vertebrae through haematogeneous spread from primary focus in the lung or another exra-osseous foci such as genitourinary, gastrointestinal or lymph nodes ${ }^{6}$.

Very little has been documented about the disease in Sudan, though high endemicity of tuberculosis in some regions of the country. Few studies on clinical presentation and complications of the disease were published ${ }^{7,8}$. The aim of this study is to define the most affected vertebral region of the spine in Sudanese patients with Potts disease.

\section{Patients and Methods}

This study was a cross-sectional hospital-based study conducted at Neurology Department, Shaab Teaching Hospital, and Khartoum Teaching Hopital, in the period from January, 2008 to December, 2010. Hundred patients with clinical suspicion of Pott's disease of the spine were enrolled in the study. Written consent was obtained from the patients participated in the study. The study was 
approved by the Research Ethics Committee, Faculty of Medicine, University of Khartoum. A pretested questionnaire was designed to include demographic data, history of the disease, and examination of different systems with emphasis on the CNS. $\mathrm{Hb} \%$, PCV, ESR, TWBCs and differential count were performed as routine investigations for patients with suspicion of TB infection. Imaging studies including plain radiographs of the chest and spine, CT scan, and myelography were done to detect the distribution of the disease among different regions of the spines. The characteristic radiological features on Plain radiographs along with CT scans and response to anti- tuberculous drugs were considered diagnostic to Pott's disease. Biopsies were taken from some patients as appropriate and sent for histopathologic examination. Data obtained were statistically analyzed using Statistical Package for Social Sciences (SPSS) version 16.

\section{Results}

In this study, out of hundred patients with Pott's disease of the spine, 60 patients $(60 \%)$ were females and 40 patients $(40 \%)$ were males. Pott's disease was more frequent in the age group $45-54$ years, which constitute 24 cases $(24 \%)$ of the study group, followed by the age group $15-24$ years, 23 cases $(23 \%)$. The age groups $65-74,35-$ 44 and $25-34$ constitute 22 cases $(22 \%), 16$ cases $(16 \%)$ and 15 cases $(15 \%)$ respectively. In 36 patients $(36 \%)$, Pott's disease was found in association with pulmonary tuberculosis. Midthoracic spines (T5 - T8) and lower thoracic spines (T9 - T12) were the most affected levels of the spine; where in 80 patients $(80 \%)$ was found to be affected with tuberculosis. In 20 cases $(20 \%)$ the disease affected the upper thoracic vertebrae (T1 - T4) and in 12 cases $(12 \%)$ it was in the lumbar spines. Only four patients (4\%) were having cervical spinal tuberculosis. The sacral segments were not affected in any of the study respondents.

Table 1. Distribution of cases by age.

\begin{tabular}{ccc}
\hline Age range & No of cases & $\%$ \\
\hline $45-54$ & 24 & 24 \\
$15-24$ & 23 & 23 \\
$65-74$ & 22 & 22 \\
$35-44$ & 16 & 16 \\
$25-34$ & 15 & 15 \\
\hline
\end{tabular}

Table 2. The number of the affected thoracic vertebrae by tuberculosis in the study group.

\begin{tabular}{lll}
\hline The affected part & No of cases & $\%$ \\
\hline T5 - T8 (mid thoracic spine) \& T9- T12 & 80 & 80 \\
(Lower thoracic spine) & & \\
T1 - T4(upper thoracic vertebrae) & 20 & 20 \\
Lumbar spine & 12 & 12 \\
Cervical spine & 4 & 4 \\
\hline
\end{tabular}

\section{Discussion}

Tuberculosis (TB) is an infectious disease caused by mycobacterium $T B$, which affect both ancient and present populations. The disease primarily present in the lung as pulmonary $\mathrm{TB}$, but it also may invade bone leading to a characteristic lesion with a clear diagnosis ${ }^{9}$.

Pott's disease of the spine is the most common form of skeletal TB. It almost comprises about $50 \%$ of all skeletal TB cases, followed by tuberculous arthritis and extraspinal tuberculous osteomyelitis. Tuberculosis in general, and spinal TB in particular, usually affects males rather than females. ${ }^{10,11}$. Our study showed the reverse, the higher incidence of the disease was in females which might be attributed to their sensitivity to the disease and early seeking of medical care. As our results showed, TB infection mainly affects young people of both genders with bad socio-economic burden of the populations affected.

Pott's disease of the spine was believed to occur through hematogenous dissemination of bacilli early in the course of infection ${ }^{12}$; this may explains the low incidence of pulmonary TB in combination with Pott's disease of the spine. Hematogeneous spread of tuberculous bacilli can occur either via arterial or venous route. A rich vascular plexus formed from arterial arcades derived from the spinal arteries in the subcortical region of the cancellous bone of vertebral bodies. This vascular plexus facilitates spread of TB infection through para-discal parts of vertebrae. A valve-less para-vertebral venous plexus (of Batson) that allows blood to follow freely in both directions excreted by raising in intra-thoracic and intra-abdominal pressure during coughing and other expulsive actions, is thought to be responsible for central spread of infection through contagious vertebral bodies ${ }^{13}$.

Mycobacterium tuberculosis may stay dormant in the vertebra for an extended length of time before clinical manifestations may develop ${ }^{14}$.

Skeletal TB can also result from direct spread through lymphatic drainage from another focus of infection, intracanalicular spread, or direct invasion ${ }^{15,16}$. The higher affection of mid thoracic and lower thoracic levels of the spine might be due to distribution of infection from combination of haematogeneous, lymphatic and direct invasion. This is may be due to frequent involvement of mediastinal lymph nodes and pleura in pulmonary TB. The vertebral bodies lose their mechanical strength as a result of progressive destruction under the force of body weight and eventually collapse with the intervertebral joints and the posterior neural arch intact; thus, an angular kyphotic deformity is produced, the severity of which depends upon the extent of destruction, the level of the lesion, and the number of vertebrae involved ${ }^{17}$. Radiologically, the vertebral body depicts the initial changes; it becomes rarefied with loss and haziness of its bone trabecular pattern. Soon the vertebral body expands and its borders are indistinct. With progressive destruction of bone the vertebral body collapses. In its early stages, Pott's disease is difficult to diagnose radiographically ${ }^{18}$. Plain radiograph of the spine with vertebral collapse may be mistaken for compression 
fractures. The intervertebral disc space first narrows and later is obliterated. This disc space narrowing occurs either due to destruction of subcondral bone of vertebral bodies with subsequent herniation of the disc or by direct invasion of the disc itself. Paraspinal abscesses may be seen quite early, presenting as fusiform or rounded shadows of water density ${ }^{19}$. Regarding the most affected vertebral levels, our findings are similar to those internationally reported. The disease mostly involves the lower thoracic and lumbar vertebrae. In a review series of 1,997 patients on world literature, the thoracic spine was the most frequent segment involved ${ }^{20}$. Although the thoracic and thoracolumbar spines are involved most commonly, the disease may be seen in any region of the spine 21,22 . Four common sites of infection in the vertebra are more affected; para-discal, central, subligamenteous, just behind the anterior longitudinal ligament of the spine, and appendiceal ${ }^{23}$. In rare cases, spinal TB may involve two non-contagious vertebrae with sparing of their intervertebral discs and adjacent parts of vertebral bodies ${ }^{24}$. Cervical spine is an uncommon site for tuberculosis infection, so, when it occur it is very difficult to recognize and might be mistaken for malignant deposits, which are more frequent and resembles TB granulomatous inflammation ${ }^{25,26}$.

\section{Conclusions}

Spinal TB is a common type of skeletal TB. The majority of cases were found as isolated cases, and few of them were associated with pulmonary TB. The most commonly involved levels were the mid thoracic and lower thoracic spinal vertebrae, this is might be due to combination of modes of spread of infection, which include haematogeneous, lymphatic and direct invasion.

\section{Ethical Clearance}

This study was ethically cleared and approved by the Research Ethics Committee, Faculty of Medicine, University of Khartoum.

\section{Acknowledgement}

The authors would like to thank the medical and nursing staff at the Department of Neurology, Elshaab Teaching Hospital and Khartoum Teaching Hospital, for their valuable, appreciable and unlimited cooperation during the data collection phase for this study. The thanks also are due to the technical staff in the histopathology laboratory and in the radiology department at the above mentioned hospitals. Thanks also are extended to our patients who agreed to join our study voluntarily without asking from financial benefits.

\section{References}

[1] Glaziou P, Falzon D, Floyd K, Raviglione M. Global epidemiology of tuberculosis. Semin Respir Crit Care Med 2013; 34(01): 003-016
[2] Taylor GM, Murphy E, Hopkins R, Rutland P, Chistov Y. First report of Mycobacterium bovis DNA in human remains from the Iron Age. Microbiology 2007;153(4):1243-9.

[3] Sternbach G. Percivall Pott: tuberculous spondylitis. $J$ Emerg Med.1996; 1: $79-83$.

[4] Agrawal V, Patgoankar PR, Nagariya SP. Tuberculosis of the spine. J Craniovertebr Junction Spine. 2010; 1(2): 74-85

[5] Chandir S, Hussain H, Amir M, Lotia I, Khan A J, Salahuddin N, Ali F. Extrapulmonary Tuberculosis: A retrospective review of 194 cases at a tertiary care hospital in Karachi, Pakistan. JPMA 60:105; 2010

[6] Tuli SM. 3rd ed. New Delhi: Jaypee Brothers; 2004. Textbook- Tuberculosis of the skeletal system (Bones, Joints, Spine and Bursal sheaths)

[7] Ahmed EG, Elbadawi NEE, Ibrahim EK, Mohammed MM (2013) Clinical Presentation of Pott's disease of the Spine in Adult Sudanese Patients. J Med Microb Diagn 2:120.

[8] Hussein A, Eltahir AE, Elamin EA, Sidig A, El Turabi H, Gadour MO. The Pattern Of Neurological Manifestations Of Tuberculosis Among Adult Sudanese Patients. Sudan Journal of Medical Sciences, 2008;

[9] Hajdu T, Donoghue HD, Bernert Z, Fóthi E, Kővári I, Marcsik A. A case of spinal tuberculosis from the middle ages in Transylvania (Romania). Spine (Phila $\mathrm{Pa}$ 1976). $2012 ; 37(25):$ E1598-601.

[10] Garg RK, Somvanshi DS. Spinal tuberculosis: a review. $J$ Spinal Cord Med. 2011; 34(5):440-54.

[11] Abhay Nene, Shekhar Bhojraj. Results of non-surgical treatment of thoracic tuberculosis in adults. The Spine Journal 5 (2005) $79-84$

[12] .Motsitsi N. S., Chipeta M. Prognosis of Spinal Tuberculosis The Internet Journal of Orthopedic Surgery. 2007; 4 Number 2

[13] Garg RK, Somvanshi DS. Spinal tuberculosis: A review. The Journal of the Spinal Cord Medicine. 2011; 34 (5): 440 454.

[14] Chun H M., Pumarejo, R M., Akin, M T., Gumpert, B C. Thoracic Pott Disease (Tuberculous Spondylitis) Presenting as Cervical Lymphadenitis. Infectious Diseases in Clinical Practice. 2006, 14 (2); 76 - 80.

[15] Agrawal V, Patgaonkar P R, Nagariya S P. Tuberculosis of spine. J Craniovertebr Junction Spine. 2010; 1(2): 74-85.

[16] Fayad L M, Carrino J A, Fishman E K. Musculoskeletal Infection: Role of CT in the Emergency Department. RSNA, 2007, 27, 1723-1736

[17] Ünal A, Sütlaş P N, Kuşçu D Y, Kirbaş D. Development of Intramedullary Spinal Tuberculoma Three Years After The Cease of Effective Antituberculosis Therapy: A Case Report. Journal of Neurological Sciences 2006, 23, (2): 139-142

[18] Jacqueline P and Sharon S. Potts disease: Diagnosis with magnetic resonance imaging. Radiography, 2010; 16:8488 .

[19] Rajasekaran S. Kyphotic deformity in spinal tuberculosis and its management. Int Orthop. 2012; 36(2):359-65. 
[20] Fuentes F M; Gutiérrez T L; Ayala R O; Rumayor Z M; and del Prado G N. Tuberculosis of the spine. A systematic review of case series. Int Orthop. 2012; 36(2):221-31

[21] Spiegel D A, Singh G K, and Banskota A K. Tuberculosis of the Musculoskeletal System. Techniques in Orthopaedics, Lippincott Williams \& Wilkins, 2005, 20(2):167-178

[22] Zoaui et al. Patients with complicated Pott's disease: Management in a rehabilitation department and functional prognosis. Ann Phys Rehabil Med. 2012, 55(3): 190 - 200.

[23] Ansari S, Rauniyar RK, Dhungel K, Sah PL, Chaudhary P, Ahmad K, Amanuallah AF. MR evaluation of the spinal tuberculosis. Al Ameen J Med Sci 2013; 6(3) :219-225.
[24] Kaila R, Malhi AM, Mahmood B, Saifuddin A. The incidence of multiple level noncontiguous vertebral tuberculosis detected using whole spine MRI. J Spinal Disord Tech 2007;20(1):78-81.

[25] Dima-Cozma C, Mitu F, Rezus E, Arhire O, Pectu I, Grigorias C, Banu C, Cozma S. Spinal tuberculosis or bone metastases? Case report. Rev Med Chir Soc Med Nat lasi 2010; 114: 115-119.

[26] Wierzba-Bobrowicz T, Michalak E, Michalik R, Stępień T. Case report: Cervical spinal tuberculosis, Folia Neuropathol 2010; 48 (4): 300-304 